\title{
Erratum to: Prophylactic Mesh Placement in High-Risk Patients Undergoing Elective Laparotomy: A Systematic Review
}

Subramanian Nachiappan • Sheraz Markar • Alan Karthikesalingam •

Paul Ziprin • Omar Faiz

Published online: 7 May 2013

(c) Société Internationale de Chirurgie 2013

Erratum to: World J Surg

DOI 10.1007/s00268-013-2046-1

Alan Karthikesalingam's family name is correct as presented in this erratum.

The online version of the original article can be found under doi: 10.1007/s00268-013-2046-1.

S. Nachiappan $(\bowtie) \cdot$ S. Markar · P. Ziprin · O. Faiz

Department of Biosurgery and Surgical Technology, Imperial College London and Imperial College Healthcare NHS Trust,

London, UK

e-mail: subra.nachiappan@doctors.org.uk

A. Karthikesalingam

Department of Vascular Surgery, St George's Hospital,

London, UK 